\title{
No todos son lo mismo, una reflexión acerca de la medicina personalizada
}

Desde 1943, año en que Pierre Denoix, en el Instituto Gustave-Russy de París, creó el TNM tenemos una forma de estratificar los pacientes con cáncer, se fue popularizando este método, algunas de las ventajas son, que nos permite comparar experiencias y estadísticas.

El año 2001 se publicó el genoma humano y en 2011 se publicaron las secuencias genéticas de 104 casos de cánceres escamosos. A modo de ejemplo Gross y cols, secuenciaron 240 cánceres escamosos y correlacionaron la pérdida del 3p en genes p53 con una sobrevida de alrededor de $40 \%$ respecto a quienes no tenían esta alteración.

Al estudiar el genoma de los tumores/pacientes, se generará una gran disgregación de información y subgrupos de pacientes, más aún si esto termina en una toma de decisión, estudios de alto costo y especificidad podría generar países con sistemas de salud con recursos escasos, dejen de hablar el "lenguaje oncológico" universal y por tanto la toma de decisiones sea incompleta para ellos. Por otro lado a nivel de TNM, en la octava versión, se incluyen por primera vez estudios moleculares en cabeza y cuello, donde VPH y VEB toman relevancia para ciertos subsitios oncológicos.

Hay muchos otros factores no incluidos en el TNM, desde simplemente la edad, el género (hombres mueren 2 veces más que las mujeres por cáncer escamoso), factores propios del tumor, uno muy conocido por los otorrinolaringólogos es el compromiso de la comisura anterior de laringe; otros como la histología, presencia de micrometástasis, factores quirúrgicos como el margen libre, factores moleculares y muchos más Todos influyen en la sobrevida, todos tienen estudios que avalen su relevancia, ya sea como factor positivo o negativo en la sobrevida.

La realidad nacional en comparación al desarrollo y acceso adecuado e universal a tecnologías de punta como el estudio con PET/CT, utilización de cirugía robótica, estudios genéticos del tumor etc..., hacen que, nuestros pacientes se encuentren en la marginalidad de estándar internacional, por ahora en la frontera, en unos años más estaremos fuera de estándar, si no se genera una inversión significativa en recursos, estos recursos no sólo deben ser físicos, sino también humanos, mejor formación y la mantención de esta mejor formación de forma dinámica.

A nivel ético, gran discusión existe acerca de la carga genética, la que puede ser estudiada desde el tumor, pero también en algunas circunstancias puede ser estu- 
diada desde el paciente, incluso antes de que la enfermedad se exprese; al menos en Chile la legislación vigente es muy exigua; si usted o cualquiera es portador de un gen en particular, no puede ser causal de exclusión de un sistema de aseguramiento, ni ningún tipo de discriminación, pero la ley no asegura el resguardo de la información y este reglamento apenas menciona estos aspectos, fuera del contexto de la investigación científica, los derechos genéticos en Chile, están resguardados en la ley 20.120 , con una completa ausencia de mirada hacia el futuro y las potencialidades de estos temas.

La recomendación general en la literatura, es que no se tomen decisiones clínicas puntuales caso a caso, dada la gran cantidad de estudios disponibles, la literatura recomienda seguir las guías de la AJCC en su octava edición, y esperar que estos factores se vayan agregando a la clasificación en su nuevas ediciones, ya sea cuando tengan valor estadístico o nos cambien conductas; 0 generar protocolos de estudio si uno quiere "salirse de lo tradicional".

Respecto a los estudios preclínicos, o sea tener información por ejemplo en la infancia, no está recomendado a menos que nos cambie la conducta clínica; la Academia Americana de Pediatría, aconseja en general no realizar test genéticos a menos que los resultados del test cambien la conducta clínica durante la infancia de forma categórica. El cáncer de tiroides nos da el mejor ejemplo de lo anterior, por un lado, la edad es parte de los factores que se consideran en su último TNM; y por otro lado, si alguien en la familia tiene un cáncer medular de tiroides, se recomienda el estudio, para ver la presencia del gen RET, si éste se encuentra presente, se recomienda la tiroidectomía profiláctica en la infancia, un claro efecto posterior a un estudio genético específico.

Habrá que esperar un tiempo, para poder ver, si la genética y la medicina personalizada, nos confirman, lo que los clínicos sospechamos desde hace mucho tiempo, no todos son lo mismo, darle valor a la información, pero mantenerse dentro de la cancha en el caso a caso; es la mejor forma de darle una atención de acuerdo a los estándares internacionales a nuestros pacientes.

Dr. Paul Boettiger Bonnefoy

Editor

Revista Otorrinolaringología y Cirugía de Cabeza y Cuello 